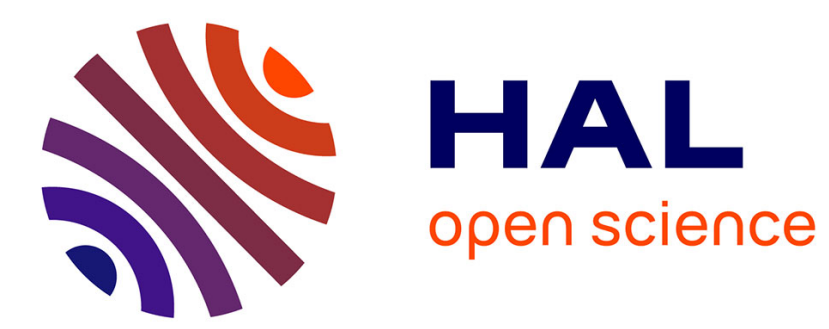

\title{
SAXS- and ASAXS-investigation of TiO2-SiO2 gels
}

Th. Gerber, B. Himmel

\section{To cite this version:}

Th. Gerber, B. Himmel. SAXS- and ASAXS-investigation of TiO2-SiO2 gels. Journal de Physique IV Proceedings, 1993, 03 (C8), pp.C8-385-C8-388. 10.1051/jp4:1993880 . jpa-00252311

\section{HAL Id: jpa-00252311 https://hal.science/jpa-00252311}

Submitted on 1 Jan 1993

HAL is a multi-disciplinary open access archive for the deposit and dissemination of scientific research documents, whether they are published or not. The documents may come from teaching and research institutions in France or abroad, or from public or private research centers.
L'archive ouverte pluridisciplinaire HAL, est destinée au dépôt et à la diffusion de documents scientifiques de niveau recherche, publiés ou non, émanant des établissements d'enseignement et de recherche français ou étrangers, des laboratoires publics ou privés. 


\title{
SAXS- and ASAXS-investigation of $\mathrm{TiO}_{2}-\mathrm{SiO}_{2}$ gels
}

\author{
Th. GERBER and B. HIMMEL
}

Universitat Rostock, Fachbereich Physik, Universitätsplatz 3, Postfach 999, 18055 Rostock, Germany

\begin{abstract}
Gels in the system $\mathrm{SiO}_{2}-\mathrm{TiO}_{2}$ were prepared by hydrolytic polycondensation of the corresponding alkoxides by use of acetyl acetone as an additive in order to reduce the rate of hydrolysis of the $\mathrm{Ti}$-alkoxide as well as by use of pre hydrolysis of the slower reacting Si-alkoxide and storage before mixing with the Ti-alkoxide. All investigated gels are characterized by very small particles varying in Guinier radius in the range between $0.8 \mathrm{~nm}$ and $1.0 \mathrm{~nm}$. These particles aggregate to form fractal clusters with a fractal dimension of nearly 2.0. Anomalous SAXS at the Ti-K-edge gives information about the behaviour of the $\mathrm{TiO}_{2}$ in the process of gelation. The resonant part of the scattering curve of the samples characterized by a high content of acetyl acetone shows that the $\mathrm{TiO}_{2}$ component is equally distributed in the system and does not take part in the formation of fractal cluster.
\end{abstract}

\section{Introduction}

One method to manufacture solids or thin films out of a "molecular construction set" is the catalytic hydrolysis and polycondensation of tetra-alkoxides in alcoholic environment. By choosing the chemical conditions it is possible to control the reaction kinetics of structure formation and, thus, the properties of the gels produced. The hydrolysis and polycondensation of the corresponding metal-ethoxides differ drastically from each other. It is necessary to harmonize this process to get an homogenous gel or a stabilised sol.

There are several possibilities for preparing homogeneous $\mathrm{TiO}_{2}-\mathrm{SiO}_{2}$-gels:

a)Increase of the reaction rate of the Si-alkoxide in relation to Ti-alkoxide

b)Pre bydrolysis of the slower reacting Si-alkoxide

c) Use of double alkoxides

d)Decrease of the reaction rate of the Ti-alkoxide by use of hydrolysis controlled chemical additives (HCCA).

In the following Small Angle X-ray Scattering (SAXS) and Anomalous SAXS are used to investigate the structure forming in the system: $\mathrm{SiO}_{2} \mathrm{TiO}_{2}$.

\section{Experimental}

In a first series we take $0.3 \mathrm{~mol}$ TEOS, $0.7 \mathrm{~mol} \mathrm{TEOTi,} 10 \mathrm{~mol} \mathrm{H}_{2} \mathrm{O}$, the catalyst $(0.2 \mathrm{~mol} \mathrm{HCl})$ and the solvent $\left(0.5 \mathrm{~mol} \mathrm{C}_{2} \mathrm{H}_{5} \mathrm{OH}\right.$ ) in this fixed ratio and vary only the quantity of acetyl acetone (HCCA) in the range from 0.03 to $0.6 \mathrm{~mol}$. A second series with a two step process was carried out. 
The ageing time of the Si-ethoxide sol was varied before the Ti-ethoxide was added to the solution (0.4 mol TEOS, $0.6 \mathrm{~mol} \mathrm{TEOTi,} 8 \mathrm{~mol} \mathrm{H}_{2} \mathrm{O}, 35 \mathrm{~mol} \mathrm{C}_{2} \mathrm{H}_{5} \mathrm{OH}$ ).

The SAXS-measurements were performed with a slit collimation (Kratky Kompact Kamera) and position sensitive detector (Braun OED-50 M).

ASAXS measurements were carried out at the SAXS-beamline A1 at the HASYLAB [1].

\section{Results}

In Figure 1 representative scattering curves of the first series are shown. The results are summarized in table 1 . All gels are characterized by very small primary particles varying in Guinier radius in the range between 0.8 and $1.0 \mathrm{~nm}$.

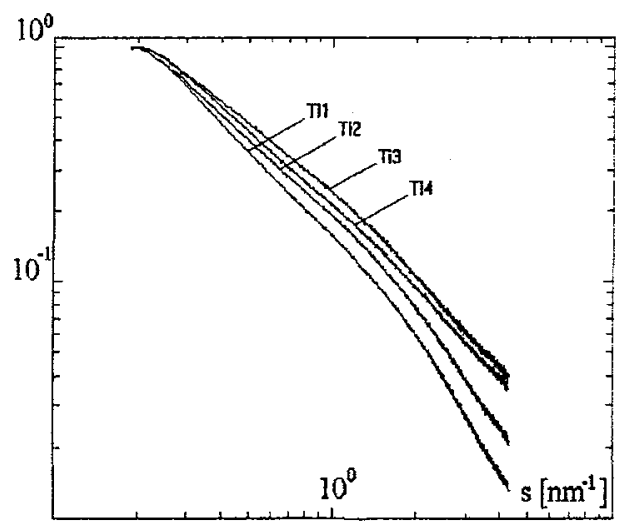

Figure I SAXS curves of the gel of series 1 with 0.15 , $0.12,0.09$ and 0.09 and $0.06 \mathrm{~mol}$ acetyl acetone (Til..Ti4)

These particles aggregate to form fractal cluster of fractal dimension $d_{f}$. The addition of acetyl acetone has a minor influence on the gel structure for acetyl acetone contents up to $0.15 \mathrm{~mol}$. The aim of our chemical procedure was to reach a nearly homogenous distribution of the two components on the molecular level. However, in two-component systems there is no possibility to distinguish between the particular components by means of normal SAXS-experiments. Anomalous SAXS at the Ti-K-edge should give information about the behaviour of the $\mathrm{TiO}_{2}$ in the process of gelation.

The measured intensity $\operatorname{Sm}(s, \lambda)$ (s-amount of the scattering vector, $\lambda$-wavelength) consists of the non-resonant part $S_{O}(s)$, the cross-term $S_{O R}(s)$, the resonant part $S_{R}(s)$ and the fluorescence Flu according to [2] with :

$$
\mathrm{S}_{\mathrm{m}}(\mathrm{s}, \lambda)=\mathrm{S}_{\mathrm{O}}(\mathrm{s})+2 * \mathrm{f}(\lambda)^{*} \mathrm{~S}_{\mathrm{OR}}(\mathrm{s})+\left(\mathrm{f} 2(\lambda)+\mathrm{f}^{\prime \prime} 2(\lambda) * \mathrm{~S}_{\mathrm{R}}(\mathrm{s})+\mathrm{fl}(\lambda) * \mathrm{Flu}\right.
$$

The dispesion term $f^{f}$ and the absorption term $\mathrm{f}^{\prime \prime}$ of the correction are calculated from the energy dependent absorption curve of the sample.

\begin{tabular}{|c|c|c|}
\hline Sample & CLUSTER & PRIMARY PARTICLES \\
\hline HCCA [mol] & $\mathrm{d}_{\mathrm{f}}$ & $\mathrm{R}_{\mathrm{G}}[\mathrm{nm}]$ \\
\hline 0.15 & 2.20 & 1.03 \\
\hline 0.12 & 2.08 & 0.98 \\
\hline 0.09 & 1.96 & 0.92 \\
\hline 0.06 & 2.05 & 0.88 \\
\hline 0.03 & 2.05 & 0.82 \\
\hline
\end{tabular}

Table 1: $R_{G}$ - Guinier radius; $d_{f}$ - fractal dimension

By making ASAXS-measurments at more than three energies near the absorption edge the partial scattering parts of equation (1) can be extracted.

We measured our samples at 6 or more different energies. That is why the equation system is over determined. It was solved bv least square method. 


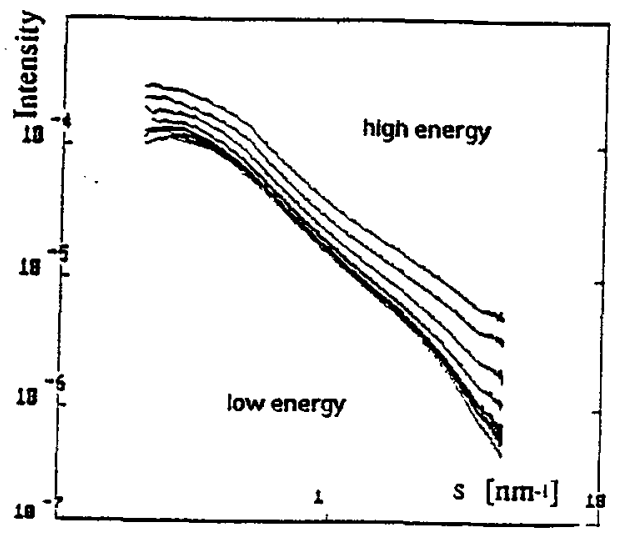

Figure 2: Scattering curve of sample with $0.15 \mathrm{~mol}$ acetyl acetone measured in the energy range between 4890 and $4990 \mathrm{keV}$.

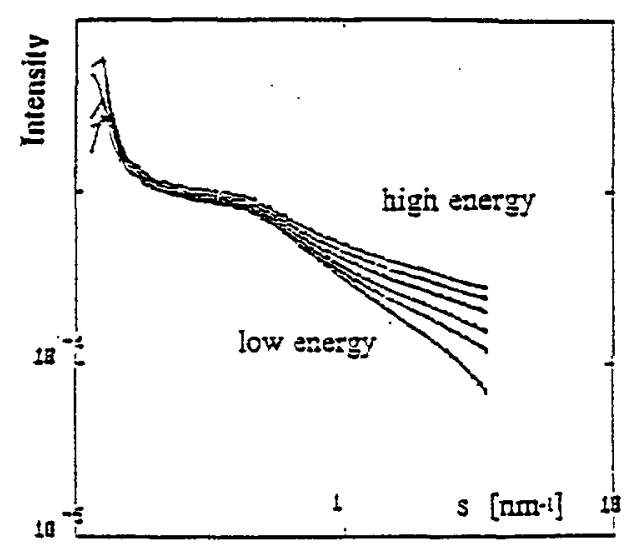

Figure 4: Scattering curves of the sample with $0.6 \mathrm{~mol}$ acetyl acetone

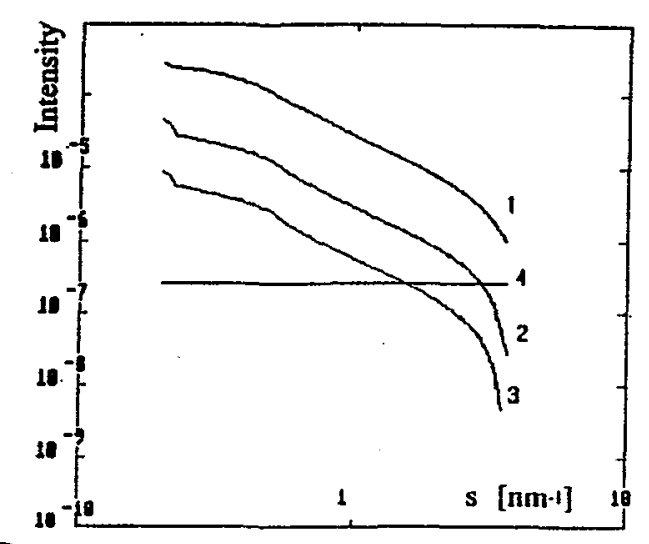

Figure 3: Scattering terms obtained by dispersion analysis of the curves of figure 2 .

1 - non resonant term; 2 -cross term: 3-resonant term; 4flurescence term

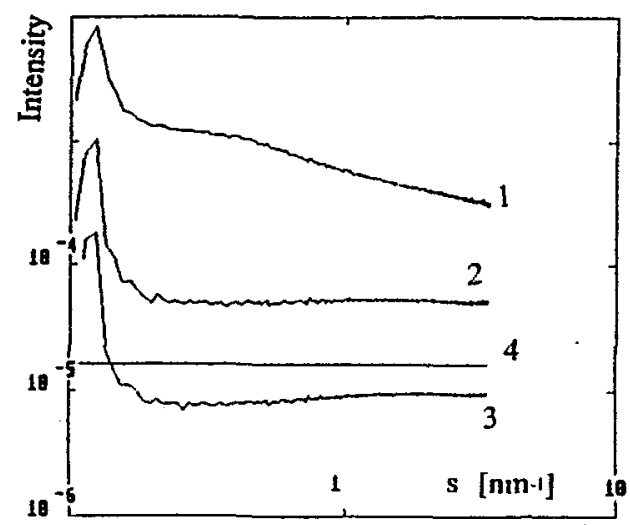

Figure 5: Result of the dispersion analysis of the curves of figure 4

Figure 2 shows the scattering curves at energies between 4890 and $4990 \mathrm{keV}$ of the sample with $0.15 \mathrm{~mol}$ acetyl acetone. The samples with less than $0.15 \mathrm{~mol}$ acetyl acetone look like this example. The scattering curves measured at higher energies are shifted nearly parallel to the curve with the lowest energy. That means the resonant part and the cross term of the scattering curve which are involved only at higher energies have the same pattern than the non resonant part. The solution of the equation system represented in figure 3 shows the same result. That means $\mathrm{SiO}_{2}$ and $\mathrm{TiO}_{2}$ take part in the aggregation process with equal rights.

With the increase of the content of acetyl acetone the relation between the aggregation probability of $\mathrm{SiO}_{2}$ and $\mathrm{TiO}_{2}$ change clearly. The energy dependent scattering curves of the sample with $0.6 \mathrm{~mol}$ acetyl acetone are shown in figure 4 . In this case the solution of the equation system (figure 5) clears up the roll of the titanium. The resonant part and the cross term of the scattering curve do not own particle scattering. It is evident that $\mathrm{TiO}_{2}$ molecules are 
equally distributed in the gel structure of the $\mathrm{SiO}_{2}$ aggregats. They do not take part on the aggregation process.

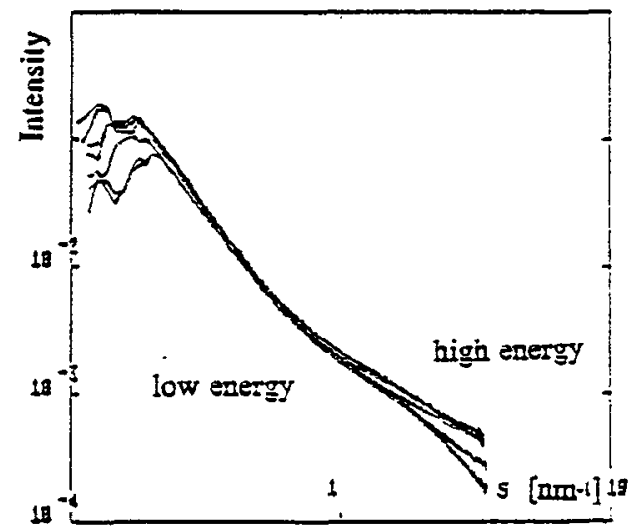

Figure 6: Scattering curves of the sample with pre hydrolysis process.

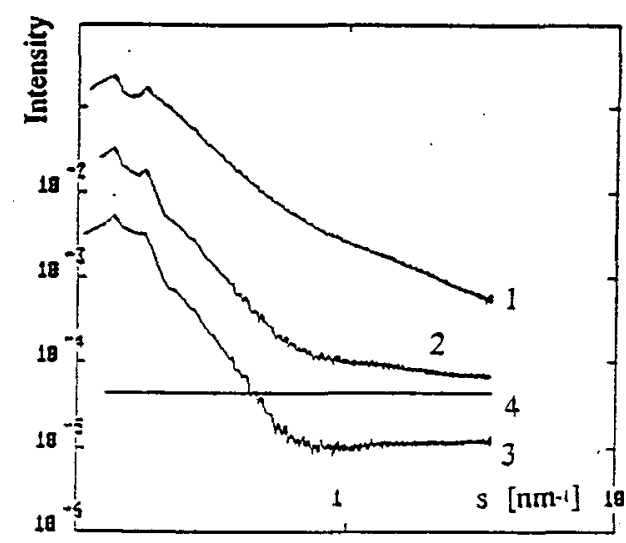

Figure 7: Result of the dispersion analysis of the curves of figure 6

The sample with the pre hydrolysis of the slower reacting Si-alkoxide shows a different scattering behaviour seen in figure 6 . Only the dispersion analysis (figure 7) permits an interpretation of experimental results. The resonant term of the scattering curve shows only for s-values smaller than $0.8 \mathrm{~nm}^{-1}$ a particle scattering. That means that $\mathrm{TiO}_{2}$ participates in formation and aggregation of the fractal clusters. But the later addition of the Ti-ethoxides prevents the formation of $\mathrm{TiO}_{2}$ primary particles. The $\mathrm{TiO}_{2}$ monomers take directly place in the aggregation of the available $\mathrm{SiO}_{2}$ - clusters.

\section{Acknowledgements}

The authors thank H. Bürger, U. Bräutigam and R. Flammersheim for the preparation of the samples and for useful discussions. We gratefully acknowledge the support of this resarch by the DFG(grant U1 110/1) and by the BMFT (grant 05 5HRAAI 6).

[1] Goerigk, G.; "Untersuchung von Metallsystemen mit Hilfe der resonanten Röntgenstreuung" PhD thesis, Universität Hamburg (1988)

[2] Stuhrmann, H.B. ;Adv in Polymer Science

Springer-Verlag Berlin/Heidelberg (1985), 67,124-163 